\title{
Information Advantage in Cournot Oligopoly ${ }^{1}$
}

\author{
Ezra Einy
}

Department of Economics, Ben Gurion University of the Negev, Beer Sheva, Israel 84105

einy@bgumail.bgu.ac.il

\section{Diego Moreno}

Departmento de Economía, Universidad Carlos III de Madrid, 28903 Getafe, Spain dmoreno@eco.uc3m.es

and

\author{
Benyamin Shitovitz \\ Department of Economics, University of Haifa, Haifa, Israel 31905 \\ binya@econ.haifa.ac.il
}

Received October 5, 2000; final version received March 6, 2001;

published online March 13, 2002

\begin{abstract}
Consider an oligopolistic industry where firms have access to the same technology but are asymmetrically informed about the environment. Even though it is commonplace to think that in this context superior information leads to higher profits, we find that under Cournot competition this is not generally the case: It holds when firms' technology exhibits constant returns to scale, but it does not necessarily hold otherwise. Journal of Economic Literature Classification Numbers: C72, D43, L13. ( 2002 Elsevier Science (USA)
\end{abstract}

Key Words: oligopoly; information advantage; Cournot competitition.

\section{INTRODUCTION}

Consider an oligopolistic industry in which firms have access to the same technology but are asymmetrically informed about the environment (e.g.,

${ }^{1}$ We thank an associate editor and participants of seminars at UCSD, Caltech, University of Arkansas, and University of Arizona for their comments. This work was done while Einy and Shitovitz visited the Department of Economics of the Universidad Carlos III de Madrid. The research of Einy and Shitovitz was supported by The Israel Science Foundation. Moreno acknowledges the support of the Spanish Ministry of Education, Grant PB97-0091.

Please address correspondence to: Diego Moreno, Departmento de Economía, Universidad Carlos III de Madrid, 28903 Getafe, Spain (dmoreno@eco.uc3m.es). 
about the demand and/or the cost function). It is commonplace to think that, in this context, superior information gives a competitive advantage and therefore leads to higher profits; i.e., ceteris paribus, if Firm A has an information advantage over Firm B, then in any Bayesian equilibrium the ex-ante expected profits of Firm A are greater than or equal to those of Firm B. This is obviously the case in a competitive market, where each firm faces an individual decision problem. We investigate whether this presumption is correct under Cournot competition, and we find that, as the example below shows, this it is not generally the case. We show, however, that the presumption is correct when firms' technology exhibits constant returns to scale. We establish these results in a general framework that imposes no restrictions on the space of states of nature or on firms' information. (In particular, firms' information can be either continuous or discrete.)

There is an extensive literature studying the role of information in oligopolistic markets under uncertainty. This literature has focused attention on the incentives for information sharing, as well as on the value of information - see, e.g., Gal-Or [8, 9], Raith [19], Sakai [20], Shapiro [21], and Vives $[22,23]$. Few papers have studied the effect of the information advantage of a firm on its profits. Note that studying this issue - whether the information advantage reflects on profits - involves comparing the profits of firms with different information in the Bayesian equilibria of a (fixed) game. In contrast, determining the value of information or the incentives for revealing information involves comparing the profits of a (given) firm in Bayesian equilibria of different games.

Gal-Or [10] shows that in a Stackelberg equilibrium the leader may be worse off having information that a follower can infer. Our exercise, in contrast to Gal-Or's, isolates the role of information by forcing the symmetry of firms in all aspects (costs, strategy sets) other than information. Also, Gal-Or [11] studies this issue in a two-period linear duopoly where firms are uncertain about costs and shows that the worse informed firm may produce more in the first period and obtain higher ex-ante profits than the better informed firm. This result, which seems at odds with the theorem below, is driven by the assumption that the accuracy of a firm's signal increases with its output during the first period. Vives [24], in a model where firms first invest (to reduce their cost or to foster their demand) and then, after the state of nature has been realized, compete in the market, finds that an increase in the accuracy of the information of a firm leads to higher profits. In Vives' model, however, competition takes place after the information has been revealed, whereas in our model firms compete under asymmetric information.

The issue of information advantage has been also a recurrent topic in other settings; e.g., Milgrom [17], Milgrom and Weber [18], and Einy et al. 
[4] study this issue in auctions; Koutsougeras and Yannelis [14], Krasa and Yannelis [15], and Einy et al. [5] study it in exchange economies with differential information.

\section{THE MODEL AND THE RESULT}

Consider an oligopolistic industry where a group of firms $N=\{1, \ldots, n\}$, $n \geqslant 2$, compete in the production of a homogeneous good. There is uncertainty about the industry's demand and the firms' costs. This uncertainty is described by a probability space $(\Omega, \mathscr{F}, \mu)$, where $\Omega$ is the set of states of nature, $\mathscr{F}$ is a $\sigma$-field of subsets of $\Omega$, and $\mu$ is a $\sigma$-additive probability measure on $(\Omega, \mathscr{F})$. (We interpret $\mu$ as the common prior of the firms.) Once the state of nature $\omega \in \Omega$ is realized, the market demand and the firms' costs (the same for all firms) are determined. Write $p: \Omega \times \mathfrak{R}_{+} \rightarrow \mathfrak{R}$ for the inverse market demand function, and write $c: \Omega \times \mathfrak{R}_{+} \rightarrow \mathfrak{R}$ for the firms' cost function. The information of a firm $i \in N$ about the state of nature is described by a $\sigma$-subfield $\mathscr{F}_{i}$ of $\mathscr{F}$; that is, for every $A \subset \mathscr{F}_{i}$ Firm $i$ knows whether the state of nature is a member of $A$. An oligopolistic industry with differential information is thus described by a collection $I=\left(N,(\Omega, \mathscr{F}, \mu), p, c,\left(\mathscr{F}_{i}\right)_{i \in N}\right)$.

Our framework proves to be very useful in dealing with the possible information structures that may arise. An alternative model due to Harsanyi [12] represents agents' private information by a set of types and takes the set of states of nature to be the cross product of the sets of agents' types. When firms' information fields are generated by partitions, Jackson [13] has shown that both approaches are equivalent (see also Section 2 in Vohra [25]).

We now introduce the following standard definition from probability theory. Let $T$ be a set. A family $\left\{x_{t}\right\}_{t \in T}$ of random variables on $\Omega$ is called uniformly integrable if

$$
\lim _{\alpha \rightarrow \infty} \sup _{t \in T} \int_{\left\{\left|x_{t}\right| \geqslant \alpha\right\}}\left|x_{t}\right| d \mu=0 .
$$

We say that a function $f: \Omega \times \mathfrak{R}_{+} \rightarrow \mathfrak{R}$ is uniformly integrable if

(2.1) for all $x \in \mathfrak{R}_{+}$the function $f(\cdot, x)$ is $\mathscr{F}$-measurable, and

(2.2) the family $\{f(\cdot, x)\}_{x \in \mathfrak{R}_{+}}$of random variables is uniformly integrable.

Throughout the paper we assume that the inverse demand function $p$ and the cost function $c$ of any oligopolistic industry with differential information are uniformly integrable. 
Let $X$ be an integrable random variable on $(\Omega, \mathscr{F}, \mu)$, and let $\mathscr{G}$ be a $\sigma$-subfield of $\mathscr{F}$. We write $E(X \mid \mathscr{G})$ for the conditional expectation of $X$ with respect to $\mathscr{G}$, and

$$
E_{+}(X \mid \mathscr{G})=\max \{0, E(X \mid \mathscr{G})\} .
$$

Let $I$ be an oligopolistic industry with differential information. The Bayesian game associated with $I$ is the collection $G(I)=(N,(\Omega, \mathscr{F}, \mu)$, $\left.\mathfrak{R}_{+}^{n},\left(\mathscr{F}_{i}\right)_{i \in N},\left(\pi_{i}\right)_{i \in N}\right)$, where for each firm $i \in N$ the set of possible actions is $\mathfrak{R}_{+}$and its profits function $\pi_{i}: \Omega \times \mathfrak{R}_{+}^{n} \rightarrow \mathfrak{R}$ is given for all $\omega \in \Omega$ and $r=\left(r_{1}, \ldots, r_{n}\right) \in \mathfrak{R}_{+}^{n}$ by

$$
\pi_{i}(\omega, r)=r_{i} p\left(\omega, \sum_{j \in N} r_{j}\right)-c\left(\omega, r_{i}\right)
$$

We refer to $G(I)$ as the Cournot game with differential information associated with the industry $I$. In this game, a (pure) strategy for a firm $i \in N$ is an $\mathscr{F}_{i}$-measurable function $q_{i}: \Omega \rightarrow \mathfrak{R}_{+}$whose first and second moments exist. We denote by $S_{i}$ the set of all strategies for Firm $i$, and by $S$ the set $\prod_{j \in N} S_{j}$ of profiles of strategies.

Let $G(I)$ be a Cournot game with differential information. A Bayesian equilibrium is a profile of strategies $q^{*}=\left(q_{1}^{*}, \ldots, q_{n}^{*}\right) \in S$ such that for every $i \in N$ and every $q_{i} \in S_{i}$,

$$
E\left(\pi_{i}\left(\cdot, q^{*}(\cdot)\right) \mid \mathscr{F}_{i}\right)(\omega) \geqslant E\left(\pi_{i}\left(\cdot,\left(q_{i}(\cdot), q_{-i}^{*}(\cdot)\right)\right) \mid \mathscr{F}_{i}\right)(\omega),
$$

for almost every $\omega \in \Omega$. (Our assumptions on $p$ and $c$ and on the set of strategies of every firm guarantee that for all $i \in N$ and $q \in S$, and for every $\sigma$-subfield $\mathscr{G}$ of $\mathscr{F}, E\left(\pi_{i}(\cdot, q(\cdot)) \mid \mathscr{G}\right)$ exists.)

The equilibrium condition (2.3) requires that at a Bayesian equilibrium every firm maximizes its (interim) conditional expected profits at every state of nature. This condition is equivalent to requiring that each firm maximizes its ex-ante expected profits; i.e., condition (2.3) is equivalent to

$$
E\left(\pi_{i}\left(\cdot, q^{*}(\cdot)\right)\right) \geqslant E\left(\pi_{i}\left(\cdot,\left(q_{i}(\cdot), q_{-i}^{*}(\cdot)\right)\right)\right),
$$

for every $i \in N$ and every $q_{i} \in S_{i}$. This equivalence is obvious in Harsanyi's model of Bayesian games (see, e.g., Section 6.4 in Fudenberg and Tirole [7]), and it is easy to show that it also holds in our model.

As the following example shows, having superior information does not necessarily entail higher profits: in the unique Bayesian equilibrium of this duopolistic industry with differential information, the better informed firm obtains lower profits than its (worse informed) competitor. 
EXAMPLE. Let $I=\left(N,(\Omega, \mathscr{F}, \mu), p, c,\left(\mathscr{F}_{i}\right)_{i \in N}\right)$ be an oligopolistic industry with differential information where $N=\{1,2\}, \Omega=\left\{\omega_{1}, \omega_{2}\right\}, \mathscr{F}=2^{\Omega}$, $\mu\left(\left\{\omega_{1}\right\}\right)=\mu\left(\left\{\omega_{2}\right\}\right), \quad \mathscr{F}_{1}=\mathscr{F}$ (i.e., Firm 1 is completely informed) and $\mathscr{F}_{2}=\{\varnothing, \Omega\}$ (i.e., Firm 2 is completely uninformed): The market demand function is given by

$$
p\left(\omega_{1}, Q\right)= \begin{cases}120-2 Q & \text { if } 0 \leqslant Q \leqslant 60 \\ 0 & \text { otherwise }\end{cases}
$$

and

$$
p\left(\omega_{2}, Q\right)= \begin{cases}80-Q & \text { if } 0 \leqslant Q \leqslant 80 \\ 0 & \text { otherwise }\end{cases}
$$

Firms' cost function is $c(\omega, q)=q^{2}$ for all $(\omega, q) \in \Omega \times \mathfrak{R}_{+}$. The strategy profile $q^{*}=\left(q_{1}^{*}, q_{2}^{*}\right)$, where $q_{1}^{*}\left(\omega_{1}\right)=\frac{1620}{109}, \quad q_{1}^{*}\left(\omega_{2}\right)=\frac{1760}{109}, \quad$ and $q_{2}^{*}\left(\omega_{1}\right)=$ $q_{2}^{*}\left(\omega_{2}\right)=\frac{1680}{109}$, is the unique Bayesian equilibrium of the associated Cournot game with differential information $G(I)$. Direct computation yields

$$
E\left(\pi_{1}\left(\cdot, q^{*}(\cdot)\right)\right)=592.05<593.89=E\left(\pi_{2}\left(\cdot, q^{*}(\cdot)\right)\right) .
$$

As the example clearly illustrates, better information allows a firm greater flexibility, as it can fine tune its strategy depending upon the state of nature. Worse information, on the other hand, introduces the possibility of commitment. In the example, the possibility of commitment allows the uninformed firm to overproduce in the low demand state, while underproducing in the high demand state. The informed firm must then hold back its production in the low demand state. As a result, the uninformed firm obtains higher (lower) profits in the low (high) demand state than the informed firm. And for the convex cost function considered in the example, this yields higher expected profits for the uninformed firm. Hence in this example the benefit of commitment that comes from being worse informed is more valuable than the flexibility that comes from being better informed.

When marginal cost is constant, however, the effect of output on profits depends solely on the firm's marginal revenue, which is the same for all firms. In this case, the greater flexibility that comes from a firm's information advantage dominates the benefit of commitment. As a consequence, as the theorem below establishes, the information advantage of a firm is rewarded; i.e., if Firm $i$ has better information than Firm $j$, then in any Bayesian equilibrium the ex-ante expected profits of Firm $i$ are greater than or equal to those of Firm $j$. In fact, the proof establishes that the expected profits of Firm $i$ conditional or Firm $j$ 's information field are greater than or equal to those of Firm $j$ (see (2.14) below), a stronger conclusion than that stated in the theorem. 
The proof of this result for the case where one firm observes the state of nature and the other firm is completely uninformed (and the solution to the firms' profits maximization problem is interior) is straightforward: In this case, the ex-ante equilibrium profits of the uninformed firm can be computed from the first-order conditions for profit maximization (see (2.11) below). The conclusion then follows as an application of the CauchySchwartz inequality (see (2.14) below). In our model, it is a simple matter to extend this conclusion to arbitrary information structures. Also, dealing with corner solutions to a firm's profits maximization problem amounts to show that at the states of nature where this occurs the firm's profits are zero (see 2.9 below).

Even though the theorem is stated and proved here only for the case where the demand is differentiable (but not necessarily linear), it holds even when, as in Example 2, it has kinks - see Einy et al. [6] for a proof of this more general result.

TheOREM. Let $I=\left(N,(\Omega, \mathscr{F}, \mu), p, c,\left(\mathscr{F}_{i}\right)_{i \in N}\right)$ be an oligopolistic industry with differential information such that for all $\omega \in \Omega, c(\omega, \cdot)$ is affine on $\mathfrak{R}_{+}, p(\omega, \cdot)$ is non-increasing and differentiable on $\mathfrak{R}_{+}$, and its derivative $p^{\prime}$ is uniformly integrable. Let $i, j \in N$ be any two firms such that $\mathscr{F}_{i} \supseteq \mathscr{F}_{j}$ (i.e., Firm i's information field is at least as fine as that of Firm $j$ ), and let $q^{*}$ be any Bayesian equilibrium of $G(I)$. Then

$$
E\left(\pi_{i}\left(\cdot, q^{*}(\cdot)\right)\right) \geqslant E\left(\pi_{j}\left(\cdot, q^{*}(\cdot)\right)\right) .
$$

For the proof of the theorem we need the following lemma, which follows directly from the definition of conditional expectation.

Lemma. Let $I=\left(N,(\Omega, \mathscr{F}, \mu), p, c,\left(\mathscr{F}_{i}\right)_{i \in N}\right)$ be an oligopolistic industry with differential information, and let $q=\left(q_{1}, \ldots, q_{n}\right) \in S$. Then for all $k \in N$ and all $\omega \in \Omega$ we have

$$
E\left(p\left(\cdot, \sum_{i \in N} q_{i}(\cdot)\right) \mid \mathscr{F}_{k}\right)(\omega)=E\left(p\left(\cdot, q_{k}(\omega)+\sum_{i \in N \backslash\{k\}} q_{i}(\cdot)\right) \mid \mathscr{F}_{k}\right)(\omega) .
$$

With this lemma in hand we can now prove the theorem.

Proof of the Theorem. Let $I=\left(N,(\Omega, \mathscr{F}, \mu), p, c,\left(\mathscr{F}_{i}\right)_{i \in N}\right)$ be an oligopolistic industry with differential information satisfying the assumptions of the theorem, and let $i, j \in N$ be such that $\mathscr{F}_{i} \supseteq \mathscr{F}_{j}$. Without loss of generality assume that for all $\omega \in \Omega, c(\omega, 0)=0$, and let $d: \Omega \rightarrow \mathfrak{R}_{+}$denote the marginal cost function. In order to reduce notation, in the rest of the proof we identify $p(\omega, \cdot)$ with $p(\omega, \cdot)-d(\omega)$. 
Let $q^{*}$ be a Bayesian equilibrium of the Cournot game with differential information $G(I)$. Write $Q^{*}=\sum_{i \in N} q_{i}^{*}$. Since for all $k \in N$ the function $q_{k}^{*}$ is $\mathscr{F}_{k}$-measurable, by Theorem 34.3 of Billingsley [3] we have

$$
E\left(\pi_{k}\left(\cdot, q^{*}(\cdot)\right) \mid \mathscr{F}_{k}\right)=q_{k}^{*} E\left(p\left(\cdot, Q^{*}(\cdot)\right) \mid \mathscr{F}_{k}\right) .
$$

Further, for each $k \in N, q_{k}^{*}$ maximizes firm $k^{\prime} s$ conditional expected profits (given $q_{-k}^{*}$ ). Now if $\omega \in \Omega$ is such that $q_{k}^{*}(\omega)>0$, then the above lemma and the first-order conditions for maximization of Firm $k^{\prime} s$ conditional expected profits yield

$$
q_{k}^{*}(\omega) E\left(p^{\prime}\left(\cdot, Q^{*}(\cdot)\right) \mid \mathscr{F}_{k}\right)(\omega)+E\left(p\left(\cdot, Q^{*}(\cdot)\right) \mid \mathscr{F}_{k}\right)(\omega)=0 .
$$

Hence we have

$$
E\left(p\left(\cdot, Q^{*}(\cdot)\right) \mid \mathscr{F}_{k}\right)(\omega) \geqslant 0,
$$

for all $\omega \in \Omega$ satisfying $q_{k}^{*}(\omega)>0$. Also, since $q^{*}$ is a Bayesian equilibrium of $G(I)$, we have

$$
E\left(p\left(\cdot, Q^{*}(\cdot)\right) \mid \mathscr{F}_{k}\right)(\omega) \leqslant 0,
$$

for all $\omega \in \Omega$ satisfying $q_{k}^{*}(\omega)=0$. Thus, for all $k \in N$ and all $\omega \in \Omega$ we have

$$
q_{k}^{*}(\omega)>0 \Rightarrow E_{+}\left(p\left(\cdot, Q^{*}(\cdot)\right) \mid \mathscr{F}_{k}\right)(\omega)=E\left(p\left(\cdot, Q^{*}(\cdot)\right) \mid \mathscr{F}_{k}\right)(\omega)
$$

and

$$
q_{k}^{*}(\omega)=0 \Rightarrow E_{+}\left(p\left(\cdot, Q^{*}(\cdot)\right) \mid \mathscr{F}_{k}\right)(\omega)=0 .
$$

For every $k \in N$ let

$$
A_{k}=\left\{\omega \in \Omega \mid E\left(p^{\prime}\left(\cdot, Q^{*}(\cdot)\right) \mid \mathscr{F}_{k}\right)(\omega)=0\right\} .
$$

Then $A_{k} \in \mathscr{F}_{k}$, and by (2.5)-(2.8) we have

$$
E\left(\pi_{k}\left(\cdot, q^{*}(\cdot)\right) \mid \mathscr{F}_{k}\right)(\omega)=E_{+}\left(p\left(\cdot, Q^{*}(\cdot)\right) \mid \mathscr{F}_{k}\right)(\omega)=0,
$$

for all $\omega \in A_{k}$. By (2.2)-(2.4), for all $k \in N$ and all $\omega \in \Omega \backslash A_{k}$ we have

$$
q_{k}^{*}(\omega)=\frac{E_{+}\left(p\left(\cdot, Q^{*}(\cdot)\right) \mid \mathscr{F}_{k}\right)(\omega)}{E\left(-p^{\prime}\left(\cdot, Q^{*}(\cdot)\right) \mid \mathscr{F}_{k}\right)(\omega)} .
$$

Therefore (2.5), (2.7), and (2.8) yield

$$
E\left(\pi_{k}\left(\cdot, q^{*}(\cdot)\right) \mid \mathscr{F}_{k}\right)(\omega)=\frac{\left(E_{+}\left(p\left(\cdot, Q^{*}(\cdot)\right) \mid \mathscr{F}_{k}\right)\right)^{2}(\omega)}{E\left(-p^{\prime}\left(\cdot, Q^{*}(\cdot)\right) \mid \mathscr{F}_{k}\right)(\omega)}
$$


for all $k \in N$ and all $\omega \in \Omega \backslash A_{k}$. Since $\mathscr{F}_{i} \supseteq \mathscr{F}_{j}$, by Theorem 34.4 of Billingsley [3] we have

$$
E\left(Z \mid \mathscr{F}_{j}\right)=E\left(E\left(Z \mid \mathscr{F}_{i}\right) \mid \mathscr{F}_{j}\right)
$$

for every integrable random variable $Z$ on $\Omega$.

Since the function $f(x)=\max \{0, x\}$ is convex on the real line, by Jensen's inequality we have

$$
E_{+}\left(E\left(p\left(\cdot, Q^{*}(\cdot)\right) \mid \mathscr{F}_{i}\right) \mid \mathscr{F}_{j}\right) \leqslant E\left(E_{+}\left(p\left(\cdot, Q^{*}(\cdot)\right) \mid \mathscr{F}_{i}\right) \mid \mathscr{F}_{j}\right) .
$$

Let $Y=\sqrt{E\left(-p^{\prime}\left(\cdot, Q^{*}(\cdot)\right) \mid \mathscr{F}_{i}\right)}$. Then $Y \geqslant 0$ on $\Omega$ and $Y>0$ on $\Omega \backslash A_{i}$. For all $\omega \in \Omega$ define

$$
X(\omega)= \begin{cases}\frac{E_{+}\left(p\left(\cdot, Q^{*}(\cdot)\right) \mid \mathscr{F}_{i}\right)(\omega)}{Y(\omega)} & \text { if } \omega \in \Omega \backslash A_{i}, \\ 0 & \text { otherwise. }\end{cases}
$$

Since $p^{\prime}\left(\omega, Q^{*}(\omega)\right) \leqslant 0$ for all $\omega \in \Omega, X \geqslant 0$ on $\Omega$. Also, by (2.9) and the definition of $X$ we have

$$
X Y=E_{+}\left(p\left(\cdot, Q^{*}(\cdot)\right) \mid \mathscr{F}_{i}\right)
$$

and

$$
X^{2}=E\left(\pi_{i}\left(\cdot, Q^{*}(\cdot)\right) \mid \mathscr{F}_{i}\right) .
$$

Now (2.12), (2.13), and the Cauchy-Schwartz Inequality yield

$$
\begin{aligned}
\left(E_{+}(\right. & \left.\left.p\left(\cdot, Q^{*}(\cdot)\right) \mid \mathscr{F}_{j}\right)\right)^{2} \\
& =\left(E_{+}\left(E\left(p\left(\cdot, Q^{*}(\cdot)\right) \mid \mathscr{F}_{i}\right) \mid \mathscr{F}_{j}\right)\right)^{2} \\
& \leqslant\left(E\left(X Y \mid \mathscr{F}_{j}\right)\right)^{2} \\
& \leqslant E\left(X^{2} \mid \mathscr{F}_{j}\right) E\left(Y^{2} \mid \mathscr{F}_{j}\right) \\
& =E\left(E\left(\pi_{i}\left(\cdot, q^{*}(\cdot)\right) \mid \mathscr{F}_{i}\right) \mid \mathscr{F}_{j}\right) E\left(E\left(-p^{\prime}\left(\cdot, Q^{*}(\cdot)\right) \mid \mathscr{F}_{i}\right) \mid \mathscr{F}_{j}\right) \\
& =E\left(\pi_{i}\left(\cdot, q^{*}(\cdot)\right) \mid \mathscr{F}_{j}\right) E\left(-p^{\prime}\left(\cdot, Q^{*}(\cdot)\right) \mid \mathscr{F}_{j}\right) .
\end{aligned}
$$

Therefore by (2.9) and (2.11) we have

$$
E\left(\pi_{j}\left(\cdot, q^{*}(\cdot)\right) \mid \mathscr{F}_{j}\right) \leqslant E\left(\pi_{i}\left(\cdot, q^{*}(\cdot)\right) \mid \mathscr{F}_{j}\right)
$$


Now, by taking integrals over $\Omega$ on both sides of (2.14) we obtain

$$
E\left(\pi_{j}\left(\cdot, q^{*}(\cdot)\right)\right) \leqslant E\left(\pi_{i}\left(\cdot, q^{*}(\cdot)\right)\right),
$$

which establishes the proposition.

Remark. The theorem above has an interesting consequence for the correlated equilibria of the games associated with oligopolistic industries with complete information. (See Aumann [1, 2], and Section 2.2 in Fudenberg and Tirole [7].) Analogously to the Bayesian equilibria of the Cournot games with incomplete information, in a correlated equilibrium relative to a correlation device for which a Firm A has an information advantage over Firm B, the profits of Firm A are greater than or equal to the profits of Firm B. A formal statement of this observation can be found in Einy et al. [6]. The set of correlated equilibria of linear Cournot oligopoly is studied in Liu [16].

\section{REFERENCES}

1. R. J. Aumann, Subjectivity and correlation in randomized strategies, J. Math. Econ. 1 (1974), 67-96.

2. R. J. Aumann, Correlated equilibrium as an expression of Bayesian rationality, Econometrica 55 (1987), 1-18.

3. P. Billingsley, "Probability and Measure," Wiley, New York, 1995.

4. E. Einy, O. Haimanko, R. Orzach, and A. Sela, Information advantage and dominant strategies in second-price common value auctions, CORE Discussion Paper 00/55, Université Catholique de Louvain.

5. E. Einy, D. Moreno, and B. Shitovitz, Competitive and core allocations in large economies with differential information, Econ. Theory 18 (2001), 321-332.

6. E. Einy, D. Moreno, and B. Shitovitz, Information advantage in Cournot oligopoly, Working Paper 99-34, Universidad Carlos III de Madrid.

7. D. Fudenberg and J. Tirole, "Game Theory,” MIT Press, Cambridge, MA, 1991.

8. E. Gal-Or, Information sharing in oligopoly, Econometrica 53 (1985), 329-343.

9. E. Gal-Or, Information transmission - Cournot and Bertrand equilibria, Rev. Econ. Stud. 53 (1986), 85-92.

10. E. Gal-Or, First mover disadvantages with private information, Rev. Econ. Stud. 54 (1987), 279-292.

11. E. Gal-Or, The advantages of imprecise information, RAND J. Econ. 19 (1988), 266-275.

12. J. C. Harsanyi, Games with incomplete information played by Bayesian players, Parts I-III, Management Science 14 (1967-1968), 159-182, 320-334, and 486-502.

13. M. Jackson, Bayesian implementation, Econometrica 59 (1993), 461- 477.

14. L. C. Koutsougeras and N. C. Yannelis, Incentive compatibility and information superiority of the core of an economy with differential information, Econ. Theory 3 (1993), 195-216.

15. S. Krasa and N. C. Yannelis, The value allocation of an economy with differential information, Econometrica 62 (1994), 881-900.

16. L. Liu, Correlated equilibrium of Cournot oligopoly competition, J. Econ. Theory 68 (1996), $544-548$. 
17. P. Milgrom, "The Structure of Information in Competitive Bidding," Garland Press, New York, 1979.

18. P. Milgrom and R. J. Weber, A theory of auctions and competitive bidding, Econometrica 50 (1982), 1089-1122.

19. M. Raith, A general model of information sharing in oligopoly, J. Econ. Theory 71 (1996), 260-288.

20. Y. Sakai, The value of information in a simple duopoly model, J. Econ. Theory 36 (1985), 71-94.

21. C. Shapiro, Exchange of cost information in oligopoly, Rev. Econ. Stud. 53 (1986), 213-232.

22. X. Vives, Aggregation of information in large Cournot markets, Econometrica 56 (1988), 851-876.

23. X. Vives, Duopoly information equilibrium: Cournot and Bertrand, J. Econ. Theory 34 (1984), 71-94.

24. X. Vives, Information and competitive advantage, Int. J. Ind. Organ. 8 (1990), 13-35.

25. R. Vohra, Incomplete information, incentive compatibility and the core, J. Econ. Theory 86 (1999), 123-147. 